\title{
A prospective Swedish study on body size, body composition, diabetes, and prostate cancer risk
}

\author{
P Wallström*,', A Bjartell ${ }^{2,4}$, B Gullberg', H Olsson ${ }^{3,5}$ and E Wirfält' \\ 'Nutrition Epidemiology Research Group, Department of Clinical Sciences, Lund University, Malmö, Sweden; ${ }^{2}$ Division of Urological Cancers, Department \\ of Clinical Sciences, Lund University, Malmö, Sweden; ${ }^{3}$ Cancer Epidemiology Unit, Section V, Department of Clinical Sciences, Lund University, Lund, \\ Sweden
}

\begin{abstract}
Obesity may be associated with increased risk of prostate cancer (PCa). According to one hypothesis, obesity could lower the risk of non-aggressive tumours, while simultaneously increasing the risk of aggressive cancer. Furthermore, central adiposity may be independently associated with PCa risk; it is also associated with diabetes, which itself may influence risk of PCa. We studied the associations between height, body composition, and fat distribution, diabetes prevalence and risk of total, aggressive, and nonaggressive PCa in 10564 initially cancer-free men (aged 45-73 years) of the population-based Malmö Diet and Cancer cohort. Anthropometric and body composition measurements, including bioelectrical impedance for estimation of fat mass, were performed by study nurses. Diabetes prevalence was self-reported. Cancer cases and clinical characteristics were ascertained through national and regional registry data. Dietary and other background data were obtained through a modified diet history method and an extensive questionnaire. During a mean follow-up of 11.0 years, 817 incidental PCa cases were diagnosed. Of these, 28I were classified as aggressive. There were 202 cases occurring before 65 years of age. Height was positively associated with total and nonaggressive PCa risk. Waist-hip ratio (WHR), a measure of central adiposity, was positively associated with PCa before age 65, and less strongly, with total PCa. This association was independent of body mass index (BMI) and other potential confounders. General adiposity, expressed as BMI or body fat percentage, and prevalent diabetes were not associated with PCa risk. In this study, WHR and body height were stronger PCa predictors than general adiposity.

British Journal of Cancer (2009) 100, 1799- 1805. doi:I0.1038/sj.bjc.6605077 www.bjcancer.com
\end{abstract}

Published online 12 May 2009

(c) 2009 Cancer Research UK

Keywords: prostatic neoplasms; cohort studies; body composition; body fat distribution; body height (or diabetes mellitus)

Obesity has long been associated with increased risk of prostate cancer (PCa), although studies have been inconsistent (MacInnis and English, 2006). Risk has been suggested to differ according to tumour grade: obesity lowering the risk of indolent, less aggressive tumours, whereas increasing that of aggressive cancer (Freedland et al, 2006), a view supported by a meta-analysis (MacInnis and English, 2006), and, to some extent, by other work (Gong et al, 2006; Littman et al, 2007; Rodriguez et al, 2007; Wright et al, 2007). Most studies have used body mass index (BMI) as a marker of general obesity, but it has certain limitations, particularly in men, because it does not differentiate muscle from fat mass (Willett, 1998). One solution might be to calculate fat mass and fat-free mass from bioelectrical impedance (BIA) measurements (Anonymous, 1996; MacInnis et al, 2003).

\footnotetext{
*Correspondence: Dr P Wallström, Nutrition Epidemiology Research Group, Department of Clinical Sciences, Clinical Research Centre, Malmö University Hospital, SE-205 02, Malmö, Sweden;

E-mail: peter.wallstrom@med.lu.se

${ }^{4}$ Department of Urology, Malmö University Hospital, SE-205 02, Malmö, Sweden

${ }^{5}$ Department of Oncology, Lund University Hospital, SE-22I 85, Lund, Sweden

Received 9 December 2008; revised 25 March 2009; accepted 8 April 2009; published online 12 May 2009
}

There is less support for the hypothesis that central adiposity (measured as waist circumference or waist-hip ratio, WHR) is a risk marker for PCa (MacInnis and English, 2006). Only a few prospective studies have examined this association (Giovannucci et al, 1997; Lee et al, 2001; MacInnis et al, 2003; Hubbard et al, 2004). Furthermore, central adiposity is a clinically established risk factor for non-insulin dependent diabetes mellitus (NIDDM) (Vazquez et al, 2007; Gastaldelli, 2008), and NIDDM has been associated with lower risk of PCa (Bonovas et al, 2004), both low grade and high grade (Gong et al, 2006). High insulin levels, as in insulin resistance, which often precedes NIDDM, was recently associated with lower risk of non-aggressive PCa (Stocks et al, 2007), although there was also a non-significant positive association with aggressive cancer.

Tallness has also been associated with PCa risk (Engeland et al, 2003; MacInnis and English, 2006); perhaps reflecting an influence of nutritional factors.

We investigated total, aggressive, and non-aggressive $\mathrm{PCa}$ in relation to current obesity, body composition, height, and prevalence of diabetes mellitus in a population-based cohort, including a sub-cohort of younger men.

\section{MATERIALS AND METHODS}

The background population of the Malmö Diet and Cancer (MDC) study, in Sweden's third largest city (Berglund et al, 1993), consists 
of all men born in 1923-1945 and all women born in 1923-1950 who were living in Malmö during the screening period 1991-1996 $(n=74138)$. This population was identified through national population registries, the final cohort consisting of 28098 individuals (participation rate $40.8 \%$ ). Participants were recruited through advertisements in local media and through invitation by mail. The only exclusion criteria were inadequate Swedish language skills and mental incapacity (Manjer et al, 2001, 2002); the Ethics Committee at Lund University approved the design of the MDC study (LU 51-90).

Waist circumference was measured midway between the lowest rib margin and iliac crest; hip circumference horizontally at the level of the greatest lateral extension of the hips. Bioelectrical impedance was used for estimating body composition according to manufacturer's procedures (BIA 103, RJL-systems, Detroit, MI, USA; single-frequency analyser). An algorithm (Sun et al, 2003) was used to estimate body fat (BF) from impedance. The results were highly correlated to results obtained by another algorithm, developed in a similar population (Heitmann, 1990). Estimated BF was used to calculate BF\%.

A structured multiple-choice questionnaire was used in the MDC study to collect information on sociodemographic factors, smoking status, alcohol habits, health status, use of pharmaceutical drugs, and several other factors. The agreement between baseline questionnaire and its repeat after 3 weeks was high for most variables ( $\kappa$ values $>0.75)$ (Manjer et al, 2002). The diabetes items read: 'Have you ever been treated for diabetes? Since what year?' Persons who reported using oral anti-diabetic drugs were also classified as diabetics.

The diet assessment, reported earlier (Wirfält et al, 2002), combines quantitative and semi-quantitative approaches to the entire diet, including cooking methods (Callmer et al, 1993). It consists of two parts: a 'menu book' for description of cooked meals and registration of cold (including juices and alcoholic) beverages and dietary supplements during seven consecutive days; and a 168item food questionnaire on regularly consumed foods during the past year. Data on validity (Elmståhl et al, 1996b; Riboli et al, 1997) and reproducibility (Elmståhl et al, 1996a) have been reported.

Cancer cases were ascertained by record linkage with the National Cancer Register. Cancer cases from the year 2005, additional data on tumour stage and grade, pre-diagnostic serum prostate-specific antigen (PSA) value, and reason for diagnosis (symptoms, health examination, or other) were obtained from the National Prostate Cancer Register (NPCR) (South Region). In the South Region, to which Malmö belongs, registration was started in 1996 and is at least 95\% complete. For cases diagnosed in 19911995 , the same data were manually extracted from medical records using standard routines. The National Cancer Register is known to be at least $98 \%$ complete. A validation of the NPCR data from another region showed high validity for all variables, including one used to classify non-aggressive and aggressive tumours (Sandblom et al, 2003).

Of the 11063 men in the MDC cohort, 485 were already diagnosed with cancer (excluding basal cell carcinomas) at study entry, and were therefore excluded; 14 others were excluded because of PCa diagnosis at autopsy, leaving 10564 men for analysis. They were followed until date of death, date of PCa diagnosis, or 31 December 2005, whichever came first. No participants were lost to follow-up of vital status. Among them, 817 incident cases of PCa ('total PCa'; ICD-9 code 185) occurred between baseline examination and end of follow-up. The average follow-up time in participants free of PCa at death $(n=1321)$ or at the end of follow-up $(n=8426)$ was 11.0 years.

An aggressive case ('aggressive Pca') was defined as a tumour with a clinical $\mathrm{T}$ stage of 3 or higher or tumour-positive lymph nodes (N1) or one or more distant metastases (M1) or a Gleason score of 8 or higher or a pre-treatment serum PSA value of at least $50 \mathrm{ng} \mathrm{ml}^{-1}$ (Stocks et al, 2007); tumours were also classified as aggressive (total 281) if the WHO grade was 3, and Gleason score was unavailable $(n=6)$. In cases in which at least two of T stadium, Gleason score, or PSA serum value were reported, and if none of these factors indicated an aggressive tumour, the tumour was classified as non-aggressive $(n=530)$. Staging data were unavailable or insufficient for 6 of the incident cases that with 530 cases of non-aggressive cancers were excluded from analyses comparing men with aggressive tumours with others. Details on stage and grade have been reported earlier (Wallström et al, 2007).

For PCa in younger people, we repeated all analyses in a subcohort, the $<65$ sub-cohort, the end of follow-up being either at date of death, date of PCa diagnosis, 31 December 2005, or the man's 65th birthday, whichever came first. This younger subcohort consisted of 8194 men, among whom 202 incident PCa cases (54 aggressive) occurred. Mean follow-up time for non-cases was 7.7 years.

We examined the associations between total, aggressive, and non-aggressive $\mathrm{PCa}$ incidence and height, waist circumference, waist-hip ratio (WHR), BMI, BF\%, and prevalence of diabetes. All continuous variables were divided into quintile groups. The hazard ratios (HR) of each distribution quintile (compared with the lowest), and trends across the quintiles were assessed with Cox proportional hazards regression with adjustment for age at baseline. The time variable was number of days of follow-up after baseline. Additionally, in a separate Cox analysis, BMI was divided into pre-defined categories (World Health Organization, 2000) with tests for overall differences between categories. We also performed analyses of waist circumference and WHR with adjustment for BMI, to assess risk associated with abdominal, irrespective of general, adiposity. All analyses were age-adjusted and were also performed in the $<65$ sub-cohort ( 202 cases). We then repeated the above analyses with adjustment for a number of potential confounders, selected from a survey of the current scientific literature: co-habitation status, socioeconomic index, alcohol habits, BF\%, smoking history, birth country (Sweden/ other), total calcium intake, dietary intake of eicosapentaenoic acid and docosahexaenoic acid, consumption of fruits, vegetables, and red meat. The dietary variables were adjusted for total energy intake (residual method) (Willett and Stampfer, 1998).

To further evaluate the consistency of our results, we repeated all analyses (including subgroups) in three separate sessions. In the first, we excluded asymptomatic cases (478 cases remaining in the total group). In the second, we excluded persons not born in Sweden (748 cases), and in the third, we excluded cases occurring within two years of the beginning of follow-up (691 remaining cases).

\section{RESULTS}

Height was associated with increased risk of total PCa, although the effect was limited to the highest quintile (range $182-203 \mathrm{~cm}$ ), and was most evident among non-aggressive tumours (Table 1). No other measures of body composition or fat distribution were significantly associated with PCa risk, although being underweight (BMI < 18.5) was associated with higher risks than normal weight across all PCa categories except the non-aggressive category; an association with BMI-adjusted WHR was suggested. Neither prevalent diabetes was significantly associated with PCa risk nor height in the $<65$ sub-cohort (Table 2, age-adjusted analyses), there was a weak, positive association with WHR. After adjustment for $\mathrm{BMI}$, the association was slightly stronger (HR per quintile 1.14 , $95 \%$ CI 1.03-1.26). Similarly, waist circumference (adjusted for BMI) was positively associated with risk in the $<65$ sub-cohort.

After adjustment for a number of possible confounders, the increased risk of total $\mathrm{PCa}$ associated with greater height was weakened ( $P$ for trend $=0.08$, Table 3 ). However, the highest quintile was still significantly different from the lowest $(P=0.018)$. The associations between WHR and PCa, both in total and in the 
Table I Age-adjusted hazard ratios (with lower and upper limits of $95 \%$ confidence intervals) for measures of height, obesity, and diabetes prevalence and total, aggressive, and non-aggressive cases of prostate cancer $^{\mathrm{a}}$

Incident prostate cancer, entire cohort $(n=10564)^{b}$

\begin{tabular}{|c|c|c|c|c|c|c|c|c|c|c|c|c|c|c|c|}
\hline & \multirow[b]{2}{*}{ Median } & \multirow[b]{2}{*}{ Range } & \multirow{2}{*}{$\begin{array}{c}\text { Non-cases } \\
(n=9747) \\
N\end{array}$} & \multicolumn{4}{|c|}{ All cases $(n=817)$} & \multicolumn{4}{|c|}{ Aggressive cases $(n=281)$} & \multicolumn{4}{|c|}{ Non-aggressive cases $(n=530)$} \\
\hline & & & & $\mathbf{N}$ & HR & Lower & Upper & $\mathbf{N}$ & HR & Lower & Upper & $\mathbf{N}$ & HR & Lower & Upper \\
\hline \multicolumn{16}{|l|}{ Height (cm) } \\
\hline Quintile I & 168 & $\leqslant 170$ & 1798 & 144 & 1.00 & & & 50 & 1.00 & & & 93 & 1.00 & & \\
\hline Quintile 2 & 173 & $17 \mid-174$ & 2011 & 182 & 1.20 & 0.97 & 1.49 & 71 & 1.40 & 0.97 & 2.01 & 109 & 1.10 & 0.84 & 1.46 \\
\hline Quintile 3 & 177 & $175-178$ & 2263 & 182 & 1.11 & 0.89 & 1.38 & 65 & 1.20 & 0.83 & 1.74 & 115 & 1.06 & 0.81 & 1.39 \\
\hline Quintile 4 & 180 & $179-18 \mid$ & 1536 & 116 & 1.09 & 0.85 & 1.39 & 36 & 1.06 & 0.69 & 1.63 & 80 & 1.12 & 0.83 & 1.51 \\
\hline Quintile 5 & 184 & $\geqslant 182$ & 2123 & 193 & $\begin{array}{l}1.40 \\
0.016\end{array}$ & 1.13 & 1.74 & 59 & $\begin{array}{l}1.38 \\
0.37\end{array}$ & 0.95 & 2.02 & 133 & $\begin{array}{l}1.42 \\
0.014\end{array}$ & 1.09 & 1.86 \\
\hline \multicolumn{16}{|l|}{$B M I$} \\
\hline Underweight & $\mathrm{n} / \mathrm{a}$ & $\leqslant 18.49$ & 48 & 8 & 2.09 & 1.03 & 4.22 & 4 & 2.88 & 1.06 & 7.82 & 4 & 0.60 & 0.22 & 1.61 \\
\hline Normal & $\mathrm{n} / \mathrm{a}$ & $18.50-24.99$ & 3627 & 287 & 1.00 & & & 102 & 1.00 & & & 183 & 1.00 & & \\
\hline Overweight & $\mathrm{n} / \mathrm{a}$ & $25.00-29.99$ & 4803 & 417 & 1.04 & 0.90 & 1.21 & 140 & 0.97 & 0.75 & 1.25 & 274 & 0.65 & 0.24 & 1.75 \\
\hline $\begin{array}{l}\text { Obese } \\
\text { Non-linear P }\end{array}$ & $\mathrm{n} / \mathrm{a}$ & $\geqslant 30.00$ & 1253 & 105 & $\begin{array}{l}1.04 \\
0.24^{c}\end{array}$ & 0.84 & 1.30 & 35 & $\begin{array}{l}0.95 \\
0.20^{d}\end{array}$ & 0.65 & 1.40 & 69 & $\begin{array}{l}0.65 \\
0.65^{\mathrm{e}}\end{array}$ & 0.24 & 1.78 \\
\hline \multicolumn{16}{|l|}{$B M l$} \\
\hline Quintile I & 22.2 & $\leqslant 23.4$ & 1949 & 158 & 1.00 & & & 61 & 1.00 & & & 96 & 1.00 & & \\
\hline Quintile 2 & 24.4 & $23.5-25.2$ & 1957 & 164 & 0.97 & 0.78 & 1.20 & 53 & 0.80 & 0.55 & 1.15 & 110 & 1.07 & 0.82 & 1.41 \\
\hline Quintile 3 & 26.0 & $25.2-26.8$ & 1928 & 168 & 0.98 & 0.79 & 1.22 & 59 & 0.87 & 0.61 & 1.25 & 107 & 1.04 & 0.79 & 1.38 \\
\hline Quintile 4 & 27.7 & $26.8-28.7$ & 1940 & 175 & 1.03 & 0.83 & 1.28 & 57 & 0.85 & 0.59 & 1.22 & 117 & 1.15 & 0.88 & 1.51 \\
\hline Quintile 5 & 30.6 & $\geqslant 28.7$ & 1957 & 152 & $\begin{array}{l}0.91 \\
0.67\end{array}$ & 0.73 & 1.14 & 51 & $\begin{array}{l}0.77 \\
0.27\end{array}$ & 0.53 & 1.12 & 100 & $\begin{array}{l}1.00 \\
0.80\end{array}$ & 0.76 & 1.33 \\
\hline \multicolumn{16}{|l|}{ Body fat \% } \\
\hline Quintile I & 15.7 & $\leqslant 18.3$ & 1952 & 146 & 1.00 & & & 53 & 1.00 & & & 93 & 1.00 & & \\
\hline Quintile 2 & 19.9 & $18.3-21.3$ & 1915 & 184 & 1.23 & 0.99 & 1.52 & 72 & 1.33 & 0.93 & 1.89 & 108 & 1.14 & 0.86 & 1.50 \\
\hline Quintile 3 & 22.6 & $21.3-23.8$ & 1941 & 157 & 1.04 & 0.83 & 1.31 & 54 & 0.99 & 0.68 & 1.44 & 102 & 1.06 & 0.80 & 1.41 \\
\hline Quintile 4 & 25.1 & $23.8-26.6$ & 1933 & 166 & 1.07 & 0.86 & 1.33 & 46 & 0.81 & 0.55 & 1.21 & 120 & 1.22 & 0.93 & 1.60 \\
\hline Quintile 5 & 28.8 & $\geqslant 26.6$ & 1937 & 161 & $\begin{array}{l}1.08 \\
0.98\end{array}$ & 0.86 & 1.35 & 55 & $\begin{array}{l}1.01 \\
0.25\end{array}$ & 0.69 & 1.48 & 105 & $\begin{array}{l}1.11 \\
0.37\end{array}$ & 0.84 & 1.47 \\
\hline \multicolumn{16}{|l|}{ Waist (cm) } \\
\hline Quintile I & 82 & $\leqslant 85$ & 1960 & 152 & 1.00 & & & 58 & 1.00 & & & 94 & 1.00 & & \\
\hline Quintile 2 & 88 & $86-90$ & 1947 & 146 & 0.92 & 0.74 & 1.16 & 49 & 0.81 & 0.55 & 1.19 & 96 & 0.99 & 0.74 & 1.31 \\
\hline Quintile 3 & 93 & $91-95$ & 2013 & 183 & 1.10 & 0.89 & 1.37 & 60 & 0.94 & 0.65 & 1.35 & 120 & 1.18 & 0.90 & 1.54 \\
\hline Quintile 4 & 98 & $96-101$ & 1893 & $17 \mid$ & 1.09 & 0.87 & 1.35 & 54 & 0.89 & 0.61 & 1.29 & 116 & 1.20 & 0.92 & 1.58 \\
\hline Quintile 5 & 107 & $\geqslant 102$ & 1912 & 165 & $\begin{array}{l}1.04 \\
0.35\end{array}$ & 0.83 & 1.30 & 60 & $\begin{array}{l}0.96 \\
0.99\end{array}$ & 0.67 & 1.38 & 104 & $\begin{array}{l}1.08 \\
0.26\end{array}$ & 0.82 & 1.43 \\
\hline \multicolumn{16}{|l|}{ WHR } \\
\hline Quintile I & 0.87 & $\leqslant 0.90$ & 1945 & 161 & 1.00 & & & 58 & 1.00 & & & 96 & 1.00 & & \\
\hline Quintile 2 & 0.91 & $0.90-0.93$ & 1949 & 161 & 1.02 & 0.82 & 1.27 & 53 & 0.96 & 0.66 & 1.39 & 110 & 1.04 & 0.79 & 1.36 \\
\hline Quintile 3 & 0.94 & $0.93-0.96$ & 1958 & 152 & 0.97 & 0.78 & 1.21 & 56 & 1.01 & 0.70 & 1.46 & 107 & 0.95 & 0.72 & 1.25 \\
\hline Quintile 4 & 0.97 & $0.96-0.99$ & 1913 & 187 & 1.21 & 0.98 & 1.50 & 67 & 1.23 & 0.87 & 1.75 & 117 & 1.20 & 0.92 & 1.56 \\
\hline Quintile 5 & 1.02 & $\geqslant 0.99$ & 1959 & 156 & 1.08 & 0.87 & 1.35 & 47 & 0.94 & 0.64 & 1.39 & 100 & 1.13 & 0.86 & 1.48 \\
\hline \multicolumn{16}{|l|}{ Diabetes? } \\
\hline No & $\mathrm{n} / \mathrm{a}$ & $\mathrm{n} / \mathrm{a}$ & 9336 & 790 & 1.00 & & & 273 & 1.00 & & & 511 & 1.00 & & \\
\hline Yes & $\mathrm{n} / \mathrm{a}$ & $\mathrm{n} / \mathrm{a}$ & $4 \mid 1$ & 27 & 0.78 & 0.53 & 1.14 & 8 & 0.62 & 0.31 & 1.26 & 19 & 0.87 & 0.55 & 1.37 \\
\hline & & & & & 0.20 & & & & 0.19 & & & & 0.55 & & \\
\hline \multicolumn{16}{|c|}{ Waist, adjusted for BMI } \\
\hline Quintile I & $\mathrm{n} / \mathrm{a}$ & $\mathrm{n} / \mathrm{a}$ & 1963 & 145 & 1.00 & & & 50 & 1.00 & & & 94 & 1.00 & & \\
\hline Quintile 2 & $\mathrm{n} / \mathrm{a}$ & $\mathrm{n} / \mathrm{a}$ & 1943 & 165 & 1.19 & 0.95 & 1.49 & 50 & 1.10 & 0.74 & 1.62 & 114 & 1.25 & 0.95 & 1.64 \\
\hline Quintile 3 & $\mathrm{n} / \mathrm{a}$ & $\mathrm{n} / \mathrm{a}$ & 1963 & 146 & 1.01 & 0.80 & 1.27 & 49 & 1.01 & 0.68 & 1.50 & 97 & 1.02 & 0.77 & 1.35 \\
\hline Quintile 4 & $\mathrm{n} / \mathrm{a}$ & $\mathrm{n} / \mathrm{a}$ & 1930 & 178 & 1.26 & 1.01 & 1.57 & 65 & 1.37 & 0.95 & 1.98 & 111 & 1.20 & 0.92 & 1.59 \\
\hline Quintile 5 & $\mathrm{n} / \mathrm{a}$ & $\mathrm{n} / \mathrm{a}$ & 1925 & 183 & 1.21 & 0.97 & 1.51 & 67 & 1.28 & 0.89 & 1.85 & 114 & 1.17 & 0.89 & 1.54 \\
\hline & & & & & 0.078 & & & & 0.083 & & & & 0.37 & & \\
\hline WHR, adjusted fo & or BMl & & & & & & & & & & & & & & \\
\hline Quintile I & $\mathrm{n} / \mathrm{a}$ & $\mathrm{n} / \mathrm{a}$ & 1937 & 169 & 1.00 & & & 57 & 1.00 & & & 112 & 1.00 & & \\
\hline Quintile 2 & $\mathrm{n} / \mathrm{a}$ & $\mathrm{n} / \mathrm{a}$ & 1968 & 139 & 0.89 & 0.71 & 1.12 & 48 & 0.95 & 0.65 & 1.39 & 90 & 0.85 & 0.64 & 1.12 \\
\hline Quintile 3 & $\mathrm{n} / \mathrm{a}$ & $\mathrm{n} / \mathrm{a}$ & 1926 & 181 & 1.20 & 0.97 & 1.49 & 65 & 1.36 & 0.95 & 1.95 & 115 & 1.12 & 0.86 & 1.46 \\
\hline Quintile 4 & $\mathrm{n} / \mathrm{a}$ & $\mathrm{n} / \mathrm{a}$ & 1940 & 166 & 1.11 & 0.90 & 1.38 & 56 & 1.18 & 0.82 & 1.71 & 109 & 1.07 & 0.82 & 1.39 \\
\hline Quintile 5 & $\mathrm{n} / \mathrm{a}$ & $\mathrm{n} / \mathrm{a}$ & 1945 & 162 & $\begin{array}{l}1.15 \\
0.049\end{array}$ & 0.93 & 1.43 & 55 & $\begin{array}{l}1.25 \\
0.12\end{array}$ & 0.86 & 1.81 & 104 & $\begin{array}{l}1.07 \\
0.24\end{array}$ & 0.82 & 1.40 \\
\hline
\end{tabular}

$\mathrm{BMI}=$ body mass index; $\mathrm{WHR}=$ waist-hip ratio; $\mathrm{HR}=$ hazard ratios. $P$-values in italics. ${ }^{\mathrm{a}} \mathrm{All} P$-values are for linear trends (categorical variables), except where noted. ${ }^{\mathrm{b}}$ Numbers

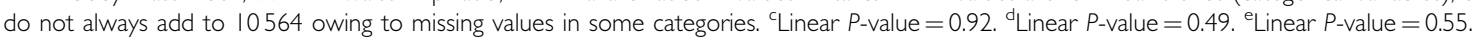

$<65$ sub-cohort, were somewhat stronger after multivariate adjustment (Tables 2 and 3). The associations with being underweight were also slightly stronger after adjustment (Table 2); otherwise, the results were similar. Inspection of the data revealed no suggestion of any significant interactions between any body measure and aggressive $v s$ non-aggressive tumours.

The association between high stature (tallest quintile) and risk of total PCa was a robust finding in most models (exclusion 
Table 2 Age-adjusted and multivariate ${ }^{a}$ hazard ratios (with lower and upper limits of $95 \%$ confidence intervals) for measures of height, obesity, and diabetes prevalence and cases of prostate cancer occurring before age $65^{\mathrm{b}}$

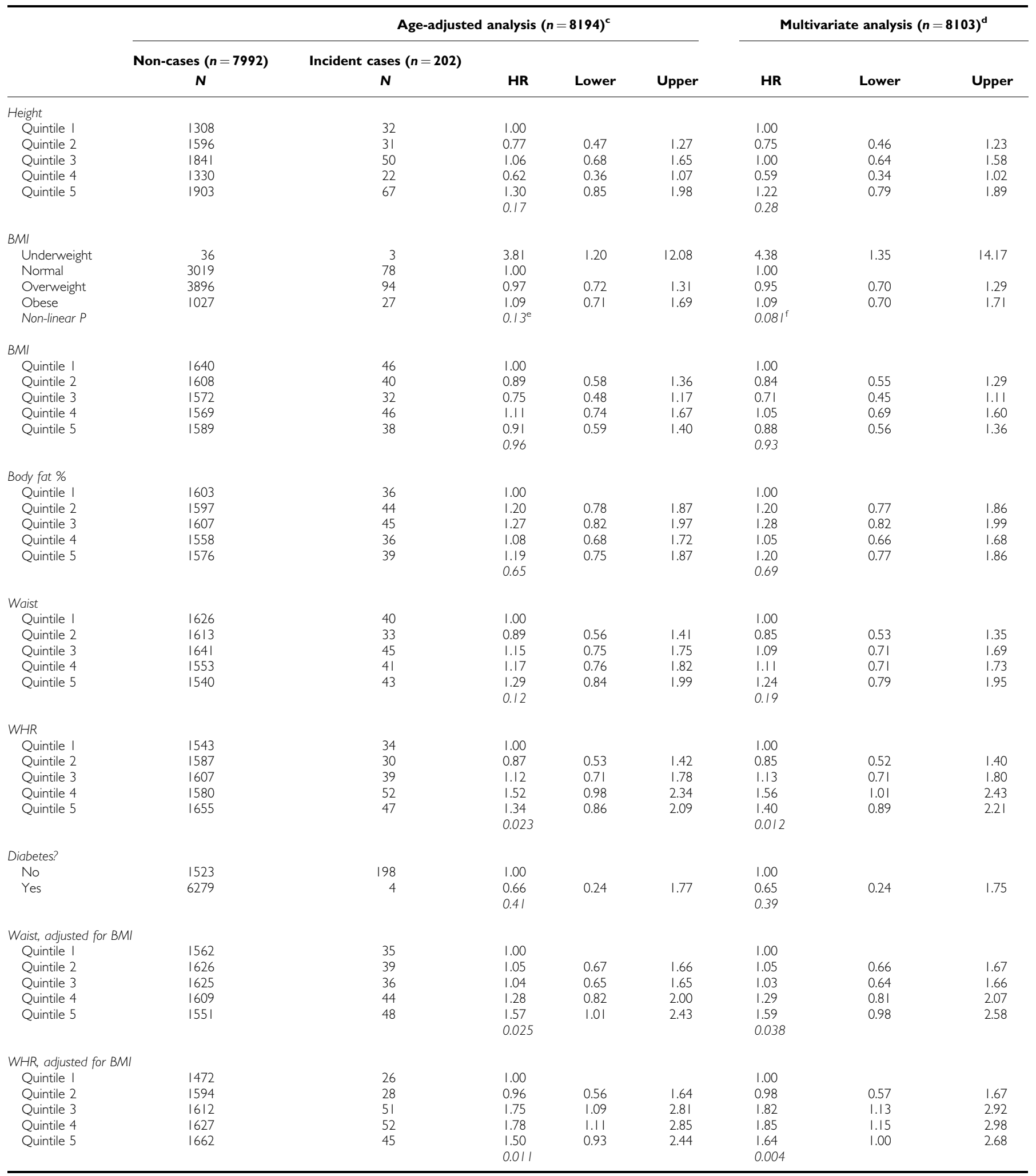

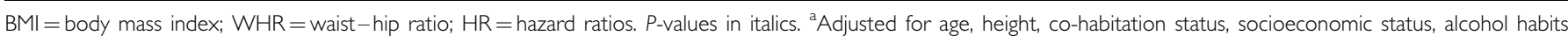
smoking habits, prevalent diabetes, total physical activity, birth country, and total intake of EPA, DHA, red meat, and calcium. Height and prevalent diabetes were further adjusted for BMI category. ${ }^{b}$ All $P$-values are for linear trends (categorical variables), except where noted. ${ }^{~}$ Numbers do not always add to 8194 owing to missing values in some categories.

${ }^{\mathrm{d}}$ Some persons excluded from the analyses because of missing values, which also affect the number of cases $(n=200)$. ${ }^{e}$ Linear $P$-value $=0.86$. ${ }^{\mathrm{f}}$ Linear $P=0.80$. 
Table 3 Multivariate adjusted hazard ratios ${ }^{\mathrm{a}}$ (with lower and upper limits of $95 \%$ confidence intervals) for measures of height, obesity, and diabetes prevalence and total, aggressive, and non-aggressive cases of prostate cancer ${ }^{b}$

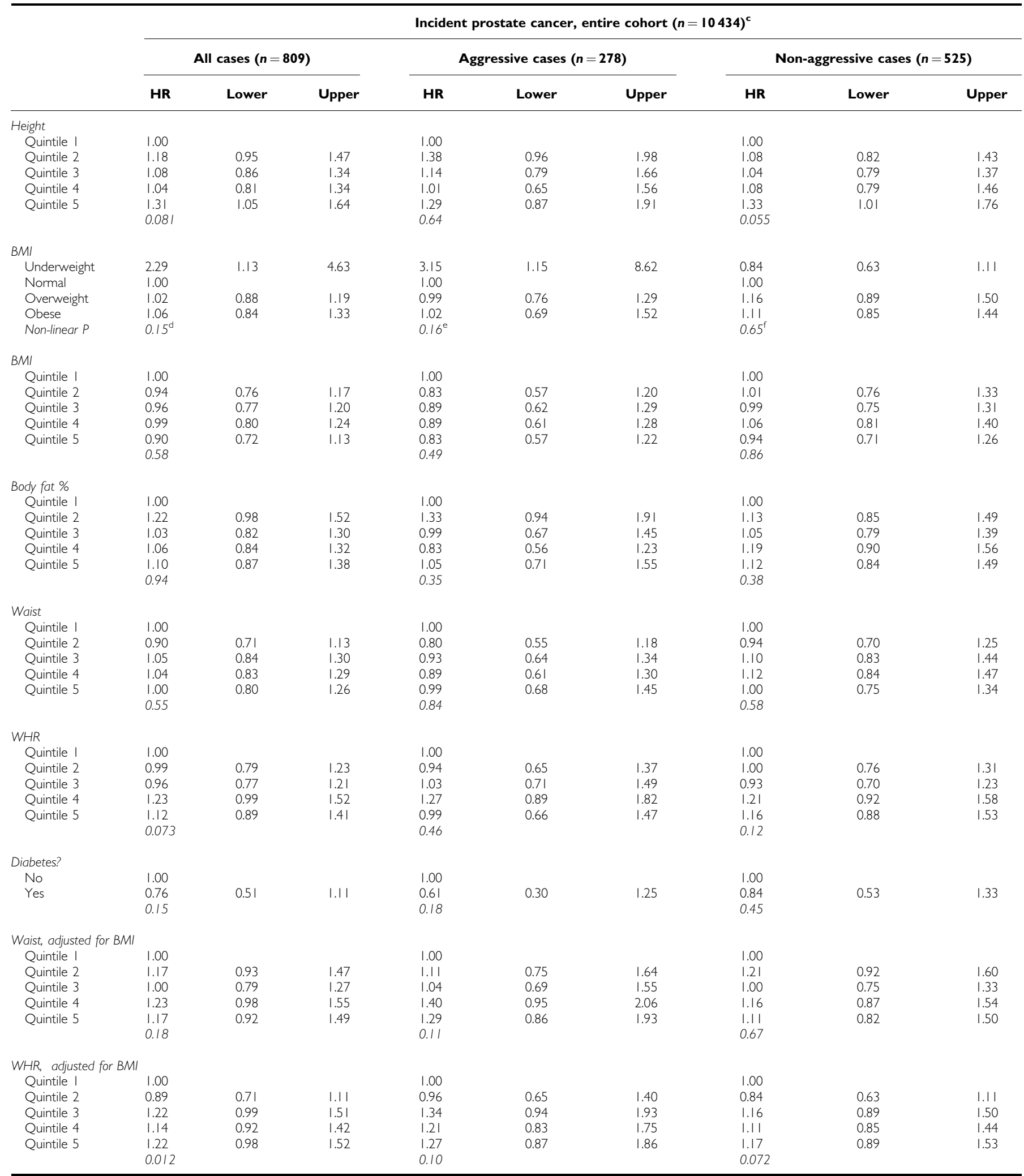

$\mathrm{BMI}=$ body mass index; WHR = waist-hip ratio; $\mathrm{HR}=$ hazard ratios. - -values are in italics. ${ }^{\mathrm{a}}$ Adjusted for age, height, co-habitation status, socioeconomic status, alcohol habits, smoking habits, prevalent diabetes, total physical activity, birth country, and total intake of EPA, DHA, red meat, and calcium. Height and prevalent diabetes were further adjusted for BMI category. ${ }^{b}$ All $P$-values are for linear trends (categorical variables), except where noted. 'Some persons excluded from the analyses because of missing values, which also affect the number of cases. ${ }^{\mathrm{d}}$ Linear $P=0.95$. ${ }^{\mathrm{e}}$ Linear $P=0.72$. ${ }^{\mathrm{f}}$ Linear $P=0.95$. 
of persons born outside of Sweden, asymptomatic cases, and cases occurring within 2 year of screening, respectively). This was true of the waist/WHR models, both univariate and multivariate. However, the association between being underweight according to BMI classification and increased risk of total $\mathrm{PCa}$ was greatly weakened after removal of cases occurring within the first 2 years or asymptomatic cases. Apart from these, the sensitivity analyses yielded no consistent results.

\section{DISCUSSION}

This study showed a weak association between tallness and risk of total PCa, also shown (but not significantly) by aggressive PCa or $\mathrm{PCa}$ in the $<65$ sub-cohort. The role of height in PCa, if any, is controversial (Gunnell et al, 2001). A similar finding was reported in the largest study to date, examining 950000 Norwegian men, in which the tallest men $(\geqslant 190 \mathrm{~cm})$ had an RR of 1.72 (95\% CI $1.46-$ 2.04) compared with the shortest (Engeland et al, 2003). Although an RR greater than 1.00 for the tallest men has been reported several times, this was not usually significant at a 0.05 level (Gunnell et al, 2001). A recent study from the EPIC cohort found no association between height and risk, neither for aggressive nor for non-aggressive tumours (Pischon et al, 2008). Furthermore, height was recently associated with increased PCa mortality (Giovannucci et al, 2007).

To our knowledge, height in itself has not been regarded as a causal factor for $\mathrm{PCa}$, but rather associations have been attributed to genetic, hormonal, and nutritional factors related to growth until adulthood, both before and after birth (Gunnell et al, 2001). As there is evidence of a positive association between body height and socioeconomic class, perhaps reflecting factors such as a greater abundance of food during growth or lower incidence of infections, one could imagine socioeconomic class confounding the association between height and PCa (Batty et al, 2006). In this study, however, this was only marginally affected by adjustment for socioeconomic index and other potential confounders.

Few studies have reported associations between waist/WHR and $\mathrm{PCa}$; a recent meta-analysis judged the evidence to be weak (MacInnis and English, 2006). In our study, WHR (and, to a smaller extent, waist) was associated with PCa, particularly before age 65 and after adjustment for BMI. Detection bias is possible: persons with higher WHR may be more likely to have other health problems and therefore visit a doctor, which could increase the chance of diagnosis. However, the sensitivity analysis showed, if anything, stronger associations when asymptomatic cases were excluded (data not shown). Although usually highly correlated with BMI, there are data to suggest that waist circumference and/or WHR may predict health problems independently of BMI, as in diabetes mellitus (Gastaldelli, 2008) and CVD (Yusuf et al, 2005). Furthermore, there is accumulating evidence for a role of waist circumference (Visscher et al, 2001; Koster et al, 2008) and WHR (Lahmann et al, 2002; Price et al, 2006) in predicting mortality independently of BMI in men. A post hoc analysis of total PCa in the present cohort shows that the increased PCa risk associated with large waist circumference seemed to be greatest at low BMI (data not shown), a finding that was not explained by prevalent asymptomatic cancer.

It is not clear why the association between WHR and PCa risk was most pronounced in the $<65$ sub-cohort, or why height was not associated with aggressive PCa. Chance findings can never be entirely ruled out; although the number of factors examined in this study was limited and well defined, the actual number of statistical tests was large. On the other hand, our findings might reflect that unmeasured factors associated with high WHR/waist circumference become relatively less important to PCa development as age increases. Similarly, height may be a marker of biological processes leading to less aggressive $\mathrm{PCa}$.

General adiposity was not associated with PCa in this study. The $\mathrm{HR}$ estimates for BF\% were slightly different from those for BMI, but not convincingly so. As the use of $\mathrm{BF} \%$ as a marker of general adiposity has recently been criticised (Cole et al, 2008), we repeated our main analyses with $\mathrm{BF} \%$ replaced by $\mathrm{BF}$ mass adjusted for lean body mass, but with broadly similar results (data not shown). One obvious explanation is that there may be no effect or a very small effect of general adiposity on PCa risk (MacInnis and English, 2006; Renehan et al, 2008), or that BF\% is not different enough from BMI to capture any differences in this respect.

Underweight $(\mathrm{BMI}<18.5)$ was associated with all categories of PCa. This may represent weight loss owing to pre-clinical cancer, particularly since the associations disappeared after exclusion of cases occurring within the first 2 years after screening.

Diabetes was not significantly associated with incidence of PCa in this study. Several studies linking NIDDM and/or insulin resistance with lower risk of PCa have been published in recent years (Bonovas et al, 2004; Gong et al, 2006; Stocks et al, 2007). As noted above, we used self-reported data on diabetes prevalence. However, because we also defined diabetics by their oral antidiabetic drug use, only diabetics without oral therapy (or who failed to record it) and who did not answer the diabetes item correctly should be misclassified. This predominantly NIDDM group may be mixed with type 1 diabetes, because the questionnaire did not differ between diabetes types. However, few persons reported age at start of diabetes treatment $<36$ years ( $n=30,12 \%$ of cases). Finally, it should be noted that our power to detect an association was rather low, because of the relatively small number of diabetics.

Many researchers use a Gleason score of $7+$ instead of $8+$ for defining more aggressive tumours. Changing our definition of aggressive to include Gleason 7 meant resulted in another 99 cases among the aggressive, with unchanged null results and weaker positive results (data not shown). This could be interpreted as an effect of diluting the aggressive group of cases by adding a large number of less malignant tumours.

In this population-based cohort study, we noted positive associations between risk of PCa and adult height, WHR, and waist circumference. No other measures of obesity or body size, or prevalent diabetes were significantly associated with $\mathrm{PCa}$ risk. There were no suggestions of significant interactions between measures of obesity and degree of aggressiveness of the tumours.

\section{ACKNOWLEDGEMENTS}

We thank Ulla Lindström, RN, Department of Urology, Malmö University Hospital, for retrieval of clinical data. We also thank the staff and participants of the Malmö Diet and Cancer Study.

Financial support has been received from the Swedish Cancer Society, the Swedish Medical Research Council, Region Skåne, The Swedish Nutrition Foundation, and the Ernhold Lundström Research Foundation.

Disclaimer: Parts of the data presented in this study are also included in a recent report from the EPIC collaboration (Pischon et al, 2008).

\section{Conflict of interest}

The authors declare no conflict of interest. 


\section{REFERENCES}

Anonymous (1996) Bioelectrical impedance analysis in body composition measurement: National Institutes of Health Technology Assessment Conference Statement 1994 Dec 12-14. Am J Clin Nutr 64(suppl): $524 \mathrm{~S}-532 \mathrm{~S}$

Batty GD, Gunnell D, Langenberg C, Davey Smith G, Marmot MG, Shipley MJ (2006) Adult height and lung function as markers of life course exposures: associations with risk factors and cause-specific mortality. Eur J Epidemiol 21: 795-801

Berglund G, Elmståhl S, Janzon L, Larsson SA (1993) The Malmö Diet and Cancer Study. Design and feasibility. J Intern Med 232: 45-51

Bonovas S, Filioussi K, Tsantes A (2004) Diabetes mellitus and risk of prostate cancer: a meta-analysis. Diabetologia 47: 1071-1078

Callmer E, Riboli E, Saracci R, kesson B, Lindgärde F (1993) Dietary assessment methods evaluated in the Malmö Food Study. J Intern Med 233: $53-57$

Cole TJ, Fewtrell MS, Prentice A (2008) The fallacy of using percentage body fat as a measure of adiposity. Am J Clin Nutr 87: 1959

Elmståhl S, Gullberg B, Riboli E, Saracci R, Lindgärde F (1996a) The reproducibility of a novel diet history method and an extensive food frequency questionnaire. The Malmö Food Study. Eur J Clin Nutr 50: $134-142$

Elmståhl S, Riboli E, Lindgärde F, Gullberg B, Saracci R (1996b) The Malmö Food Study. The relative validity of a modified diet history method and an extensive food frequency questionnaire for measuring food intake. Eur J Clin Nutr 50: 143-151

Engeland A, Tretli S, Bjørge T (2003) Height, body mass index, and prostate cancer: a follow-up of 950000 Norwegian men. $\mathrm{Br}$ J Cancer 89: $1237-1242$

Freedland SJ, Giovannucci E, Platz EA (2006) Are findings from studies of obesity and prostate cancer really in conflict? Cancer Causes Control 17: 5-9

Gastaldelli A (2008) Abdominal fat: does it predict the development of type 2 diabetes? Am J Clin Nutr 87: 1118-1119

Giovannucci E, Liu Y, Platz EA, Stampfer MJ, Willett WC (2007) Risk factors for prostate cancer incidence and progression in the health professionals follow-up study. Int J Cancer 121: 1571-1578

Giovannucci E, Rimm EB, Stampfer MJ, Colditz GA, Willett WC (1997) Height, body weight, and risk of prostate cancer. Cancer Epidemiol Biomarkers Prev 6: $557-563$

Gong Z, Neuhouser ML, Goodman PJ, Albanes D, Chi C, Hsing AW, Lippman SM, Platz EA, Pollak MN, Thompson IM, Kristal AR (2006) Obesity, diabetes, and risk of prostate cancer: results from the Prostate Cancer Prevention Trial. Cancer Epidemiol Biomarkers Prev 15: $1977-1983$

Gunnell D, Okasha M, Davey Smith G, Oliver SE, Sandhu J, Holly JMP (2001) Height, leg length, and cancer risk: a systematic review. Epidemiol Rev 23: $313-342$

Heitmann BL (1990) Prediction of body water and fat in adult Danes from measurement of electrical impedance. A validation study. Int J Obes 14: $789-802$

Hubbard JS, Rohrmann S, Landis PK, Metter EJ, Muller DC, Andres R, Carter HB, Platz EA (2004) Association of prostate cancer risk with insulin, glucose, and anthropometry in the Baltimore longitudinal study of aging. Urology 63: 253-258

Koster A, Leitzmann MF, Schatzkin A, Mouw T, Adams KF, van Eijk JTM, Hollenbeck AR, Harris TB (2008) Waist circumference and mortality. Am J Epidemiol 167: 1465 - 1475

Lahmann PH, Lissner L, Gullberg B, Berglund G (2002) A prospective study of adiposity and all-cause mortality: the Malmö Diet and Cancer Study. Obes Res 10: 361 - 369

Lee IM, Sesso HD, Paffenbarger Jr RS (2001) A prospective cohort study of physical activity and body size in relation to prostate cancer risk (United States). Cancer Causes Control 12: $187-193$

Littman AJ, White E, Kristal AR (2007) Anthropometrics and prostate cancer risk. Am J Epidemiol 165: 1271 - 1279

MacInnis RJ, English DR (2006) Body size and composition and prostate cancer risk: systematic review and meta-regression analysis. Cancer Causes Control 17: 989-1003

MacInnis RJ, English DR, Gertig DM, Hopper JL, Giles GG (2003) Body size and composition and prostate cancer risk. Cancer Epidemiol Biomarkers Prev 12: $1417-1421$

Manjer J, Carlsson S, Elmståhl S, Gullberg B, Janzon L, Lindström M, Mattisson I, Berglund G (2001) The Malmö Diet and Cancer Study: representativity, cancer incidence and mortality in participants and nonparticipants. Eur J Cancer Prev 10: 489-499

Manjer J, Elmståhl S, Janzon L, Berglund G (2002) Invitation to a population-based cohort study: differences between subjects recruited using various strategies. Scand J Public Health 30: 103-112

Pischon T, Boeing H, Weikert S, Allen N, Key T, Føns Johnsen N, Tjønneland A, Tang Severinsen M, Overvad K, Rohrmann S, Kaaks R, Trichopoulou A, Zoi G, Trichopoulos D, Pala V, Palli D, Tumino R, Sacerdote C, Bueno-de-Mesquita HB, May A, Manjer J, Wallström P, Stattin P, Hallmans G, Buckland G, Larrañaga $N$, Chirlaque MD, Martinez C, Redondo Cornejo ML, Ardanaz E, Bingham S, Khaw KT, Rinaldi S, Slimani N, Jenab M, Riboli E (2008) Body size and risk of prostate cancer in the European Prospective Investigation into cancer and nutrition. Cancer Epidemiol Biomarkers Prev 17: $3252-3261$

Price GM, Uauy R, Breeze E, Bulpitt CJ, Fletcher AE (2006) Weight, shape, and mortality risk in older persons: elevated waist-hip ratio, not high body mass index, is associated with a greater risk of death. Am J Clin Nutr 84: $449-460$

Renehan AG, Tyson M, Egger M, Heller RF, Zwahlen M (2008) Body-mass index and incidence of cancer: a systematic review and meta-analysis of prospective observational studies. Lancet 371: 569-578

Riboli E, Elmståhl S, Saracci R, Gullberg B, Lindgärde F (1997) The Malmö Food Study: validity of two dietary assessment methods for measuring nutrient intake. Int I Epidemiol 26(Suppl. 1): S161 - S173

Rodriguez C, Freedland SJ, Deka A, Jacobs EJ, McCullough ML, Patel AV, Thun MJ, Calle EE (2007) Body mass index, weight change, and risk of prostate cancer in the Cancer Prevention Study II Nutrition Cohort. Cancer Epidemiol Biomarkers Prev 16: 63-69

Sandblom G, Dufmats M, Olsson M, Varenhorst E (2003) Validity of a population-based cancer register in Sweden. Scand J Urol 37: $112-119$

Stocks T, Lukanova A, Rinaldi S, Biessy C, Dossus L, Lindahl B, Hallmans G, Kaaks R, Stattin P (2007) Insulin resistance is inversely related to prostate cancer: a prospective study in Northern Sweden. Int J Cancer 120: $2678-2686$

Sun SS, Chumlea WC, Heymsfield SB, Lukaski HC, Schoeller D, Friedl K, Kuczmarski RJ, Flegal KM, Johnson CL, Hubbard VS (2003) Development of bioelectrical impedance analysis prediction equations for body composition with the use of a multicomponent model for use in epidemiologic surveys. Am J Clin Nutr 77: $331-340$

Vazquez G, Duval S, Jacobs Jr DR, Silventoinen K (2007) Comparison of body mass index, waist circumference, and waist/hip ratio in predicting incident diabetes: a meta-analysis. Epidemiol Rev 29: $115-128$

Visscher TL, Seidell JC, Molarius A, van der Kuip D, Hofman A, Witteman JC (2001) A comparison of body mass index, waist-hip ratio and waist circumference as predictors of all-cause mortality among the elderly: the Rotterdam study. Int J Obes Relat Metab Disord 25: 1730-1735

Wallström P, Bjartell A, Gullberg B, Olsson H, Wirfält E (2007) A prospective study on dietary fat and incidence of prostate cancer (Malmö, Sweden). Cancer Causes Control 18: 1107-1121

Willett WC (1998) Anthropometric measures and body composition. In Nutritional Epidemiology, Willett WC (ed), pp 244-272. Oxford University Press: New York

Willett WC, Stampfer MJ (1998) Implications of total energy intake for epidemiologic analyses. In Nutritional Epidemiology, Willett WC (ed), pp 273-301. Oxford University Press: New York

Wirfält E, Mattisson I, Johansson U, Gullberg B, Wallström P, Berglund G (2002) A methodological report from the Malmö Diet and Cancer study: development and evaluation of altered routines in dietary data processing. Nutr J 1: 3

World Health Organization. Obesity: Preventing and Managing the Global Epidemic (2000). 894 WHO: Geneva. WHO Technical Report Series. Ref Type: Report

Wright ME, Chang SC, Schatzkin A, Albanes D, Kipnis V, Mouw T, Hurwitz P, Hollenbeck A, Leitzmann MF (2007) Prospective study of adiposity and weight change in relation to prostate cancer incidence and mortality. Cancer 109: 675-684

Yusuf S, Hawken S, Ounpuu S, Bautista L, Franzosi MG, Commerford P, Lang CC, Rumboldt Z, Onen CL, Lisheng L, Tanomsup S, Wangai Jr. P, Razak F, Sharma AM, Anand SS, INTERHEART Study Investigators (2005) Obesity and the risk of myocardial infarction in 27000 participants from 52 countries: a case-control study. Lancet 366: $1640-1649$ 